\title{
Effect of Amount of Deformation on the Martensitic Transformation and Shape Memory Effect in Fe-Mn-Si based Shape Memory Steel
}

\author{
Q. Gu, J. Van Humbeeck, L. Delaey, L. Federzoni*, G. Guénin* and D. Gex** \\ Dept. of Metallurgy and Materials Engineering, K.U. Leuven, 3001 Leuven, Belgium \\ * GEMPPM, INSA-Lyon, 69621 Villeurbanne cedex, France \\ ** Ugine Savoie, 73403 Savoie cedex, France
}

\begin{abstract}
The effect of amount of deformation on the martensitic transformation and shape memory effect in a $\mathrm{Fe}-16 \mathrm{Mn}-5 \mathrm{Si}-9 \mathrm{Cr}-4 \mathrm{Ni}$ alloy is studied. It is found that both $\varepsilon-$ and $\alpha^{\prime}-$ martensite are induced by deformation. With increasing amount of deformation, $\gamma \rightarrow \varepsilon \rightarrow \alpha^{\prime}$ transformation is greatly enhanced. the highest shape memory strain $3.8 \%$ is reached when the amount of deformation is about $5 \%$.
\end{abstract}

\section{INTRODUCTION}

It is well established that the one way shape memory effect in Fe-Mn-Si alloys results from the reverse motion of the a/6[112] Shockley partial dislocations generated during stress-induced martensitic transformation [1-3]. Many parameters can influence the martensitic transformation. Among them, the amount of deformation shows a strong influence on the shape memory effect of the alloy.

When the amount of deformation is small, only primary $\varepsilon$ variants are induced, the shape recovery is usually complete since the reverse motion of Shockley partial dislocations are not hindered. By applying a large amount of deformation, the different orientations of $\varepsilon$ variants operate in the structure. The intersection of these $\varepsilon$-martensite plates will hinder the reverse motion of partials. Meanwhile, the deformation may promote $\alpha^{\prime}$-martensite transformation. The $\alpha^{\prime}$-martensite transformation is believed to impede the shape memory effect [4]. The permanent strain also increases with the application of stress due to the work hardening in the structure, which is also unrecoverable by heating. Thus, an optimum amount of deformation must exist for reaching higher shape memory strains.

Robinson et al. [5] found that maximum shape memory strain in a polycrystalline $\mathrm{Fe}-30 \% \mathrm{Mn}-6.5 \% \mathrm{Si}$ $(w t \%)$ alloy is obtained when the pre-strain is $4 \%$. The increase of pre-strain increases both the stress required for slip and the stress required for the movement of partial dislocations associated with the transformation.

This study reveals that in the investigated alloys, $\gamma \rightarrow \varepsilon$ and $\gamma \rightarrow \varepsilon \rightarrow \alpha^{\prime}$ transformation are both induced by deformation. With increasing amount of deformation, $\alpha^{\prime}$-martensite transformation is greatly enhanced. It is found that in this study, the highest shape memory strain is reached by applying about $5 \%$ deformation. 


\section{EXPERIMENTAL}

The investigated alloy is received in the shape of hot rolled plate with a thickness of $8 \mathrm{~mm}$. The chemical composition of the alloy is Fe-16Mn-5Si-9Cr-4Ni-0.006C (wt\%). A color etching method is developed to distinguish different martensitic phases and austenitic matrix. The specimens are polished mechanically followed by an electrolytic polishing with a solution of $20 \%$ perchloric acid and $80 \%$ butylcellosolve. Then the specimens are immersed in a solution of $1.2 \% \mathrm{~K}_{2} \mathrm{~S}_{2} \mathrm{O}_{5}$ and $0.5 \% \mathrm{NH}_{4} \mathrm{HF}$ in distilled water for a few seconds. The percentage of martensitic phases is determined by $\mathrm{X}$-ray diffraction measurements using a D500 Siemens Goniometer. The shape memory effect is measured through the length change before and after compression deformation and thermal mechanical analysis.

\section{RESULTS AND DISCUSSIONS}

\subsection{Microstructural development after deformation}

The specimens after annealing at $1100^{\circ} \mathrm{C}$ for 30 minutes followed by air cooling are deformed by $0.5 \%$, $2 \%, 5 \%, 10 \%$ and $25 \%$. The microstructural observation reveals that $\alpha$-martensite appears after certain amount of deformation together with the stress-induced $\varepsilon$-martensite. As shown by Fig. 1, after $0.5 \%$, small nuclei of $\alpha^{\prime}$-martensite are observed inside $\varepsilon$-martensite plates. The increasing amount of deformation obviously induces largely the $\alpha^{t}$-martensite transformation. Fig. 2 shows the microstructure of a specimen after $25 \%$ deformation. Large amount of $\alpha$-martensite is not only observed inside the $\varepsilon$ martensite plates but also at the intersections of thin $\varepsilon$-martensite plates. The growth and intersection of $\alpha^{\prime}$-martensite is greatly enhanced, The coalescence of these $\alpha^{\prime}$-martensite can be easily found inside one plates or among several plates, indicating that the $\gamma \rightarrow \varepsilon \rightarrow \alpha^{\prime}$ transformation is strongly induced by deformation.

\subsection{Relation of amount of deformation and amount of stress-induced $\varepsilon$ - and $\alpha^{\prime}$-martensite}

Fig. 3 shows the relation of the amount of deformation with the percentage of stress-induced $\varepsilon$ martensite. The specimen is pre-annealed at $600^{\circ} \mathrm{C}$ for $15 \mathrm{~min}$. followed by air cooling. The $\mathrm{M}_{\mathrm{S}}$ is below $0^{\circ} \mathrm{C}$, no thermal $\varepsilon$-martensite plates exists at room temperature before the deformation. This figure clearly shows that with increasing amount of deformation, the amount of stress-induced $\varepsilon$-martensite increases remarkably. Below $5 \%$ deformation, the amount of stress-induced $\varepsilon$-martensite is lower than $10 \%$ and increases slowly with increasing amount of deformation. However, when the amount of deformation reaches $15 \%$, the percentage of stress-induced $\varepsilon$-martensite is around $70 \%$.

The relation of the amount of deformation with the amount of stress-induced $\alpha$-martensite is shown in Fig.4. It can be seen that below $10 \%$ deformation, the amount of $\alpha^{\prime}$-martensite that is stress-induced is around $1 \%$. Above $10 \%$ deformation, the amount of $\alpha$-martensite that can be stress-induced is increased to $4.5 \%$. With increasing amount of deformation, both the amount of stress-induced $\varepsilon$ - and $\alpha^{\prime}$-martensite are increased. The amount of $\varepsilon$-martensite that can be induced is much larger than that of $\alpha^{\prime}$-martensite. Above $10 \%$ deformation, the amount of stress-induced $\varepsilon$ - and $\alpha$-martensite are comparatively larger than that of below $10 \%$ deformation. Since the $\alpha^{\prime}$-martensite is reported to impede the reverse transformation of $\varepsilon$-martensite, the amount of deformation should be limited to around $5 \%$ in order to avoid larger amounts of $\alpha^{\prime}$-martensite forming in the structure.

\subsection{Relation of amount of deformation and shape memory strain}

The above results indicated that there exists an optimum deformation degree for reaching a higher shape memory strain. Fig. 5 shows the relation of the amount of deformation with shape memory strains of specimens annealed at $500^{\circ} \mathrm{C}$ to $1100^{\circ} \mathrm{C}$. It can be seen that the highest shape memory strains are all 
obtained when the amount of deformation is around 5\%. Below 5\% deformation, the shape memory strain is increased from around $0.3 \%$ to $1.5 \%$ with increasing amount of deformation. Above $5 \%$ deformation, the recovery strain is decreased greatly with increasing amount of deformation. It is obvious that above 5\% deformation, the slip deformation instead of stress-induced $\varepsilon$-martensite transformation dominates the deformation mechanism and also the intersections among different variants of $\varepsilon$-martensite plates are increased. All these lead to the drop of the shape memory strain.

\section{CONCLUSIONS}

1) Deformation induces both $\gamma \rightarrow \varepsilon$ and $\gamma \rightarrow \varepsilon \rightarrow \alpha^{\prime}$ transformation in a Fe-16Mn-5Si-9Cr-4Ni (wt\%) alloy. With increasing amount of deformation, the amount of stress-induced $\varepsilon$ - and $\alpha$-martensite is greatly enhanced. $\alpha^{\prime}$-martensite forms only inside and at the intersections of $\varepsilon$-martensite plates, indicating its transformation occurs through the intermediate phase $\varepsilon$-martensite. At sufficiently large strains, $\alpha^{\prime}-$ martensite appears to grow, intersect and coalescense.

2) There exists an optimum amount of deformation of $5 \%$ to reach the highest shape memory strain of $1.5 \%$ before any training treatment for the investigated alloys. after several training cycles, a maximum one way shape memory strain of $3.8 \%$ could be reached [6]. $\alpha^{\prime}$-martensite is found to be a limiting factor for improving the shape memory effect.

\section{ACKNOWLEDGEMENT}

Part of this research is conducted under the European CECA-project $7210 / \mathrm{MA} / 314$. The authors wish to thak Ugine Savoie Co. (France) for providing the materials and supporting this project. Q. Gu thanks Dept. of Metallurgy and Materials Engineering of K. U. Leuven for awarding a research scholarship and J. Van Humbeeck acknowledges the Belgian National Foundation of Science (NFWO).

\section{REFERENCES}

1. H. Fujita and S. Ueda, Acta. Metall., 20 (1972), 759-767

2. H. Inagaki, Z. Metallkd., 83 (1992), 90-96

3. J. Li and C. M. Wayman, Scripta Metall. et Mat., 27 (1992), 279-284

4. J. H. Yang, H. Chen and C. M. Wayman, Metall. Trans., 23A (1992), 1431-1437

5. J. S. Robinson and P. G. McCormick, Mat. Sci. Forum, 56-58 (1990), 649-654

6. Q. Gu, Ph. D Thesis, Dept. MTM, K. U. Leuven, May 1994 


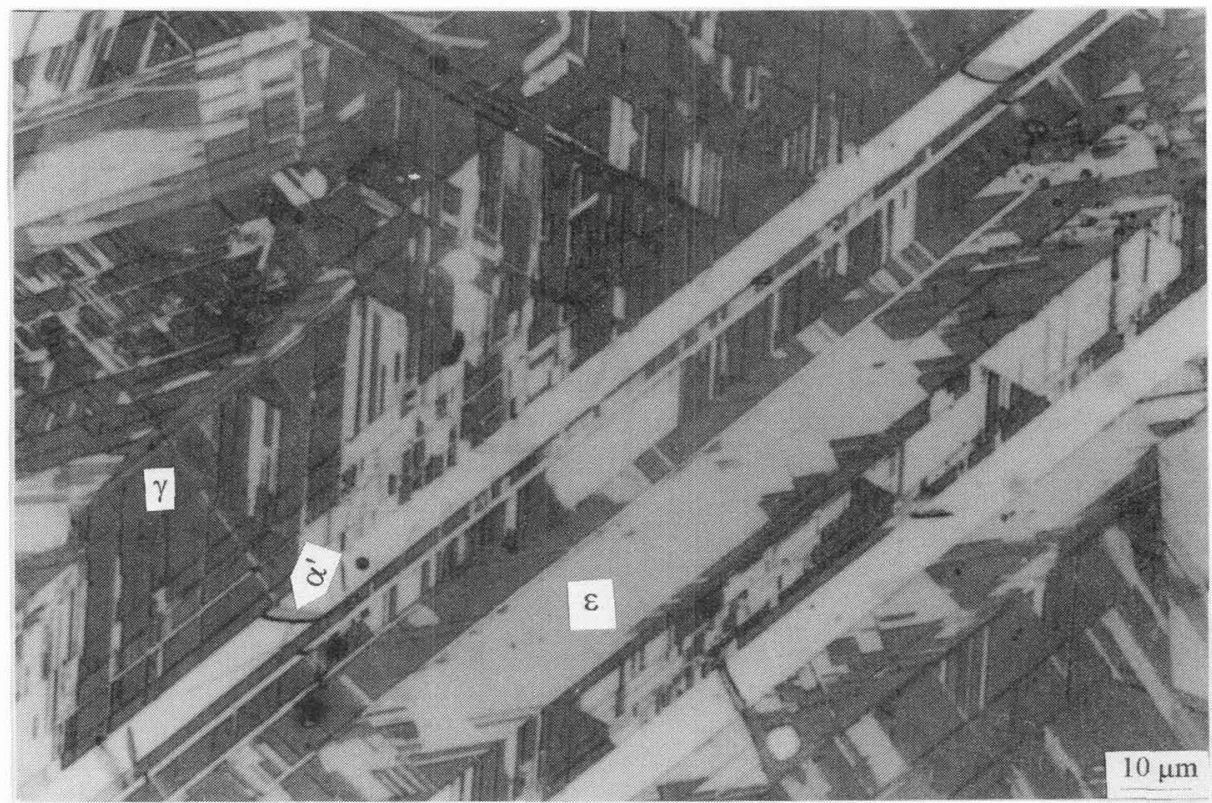

Fig.1. The black and white print of a color micrography of the specimen deformed by $0.5 \%$ showing the formation of small sizes of $\alpha^{\prime}$-martensite (black particles) inside $\varepsilon$-martensite plates (white plates). Specimen pre-annealed at $1100^{\circ} \mathrm{C}, 30$ minutes, air cooled.

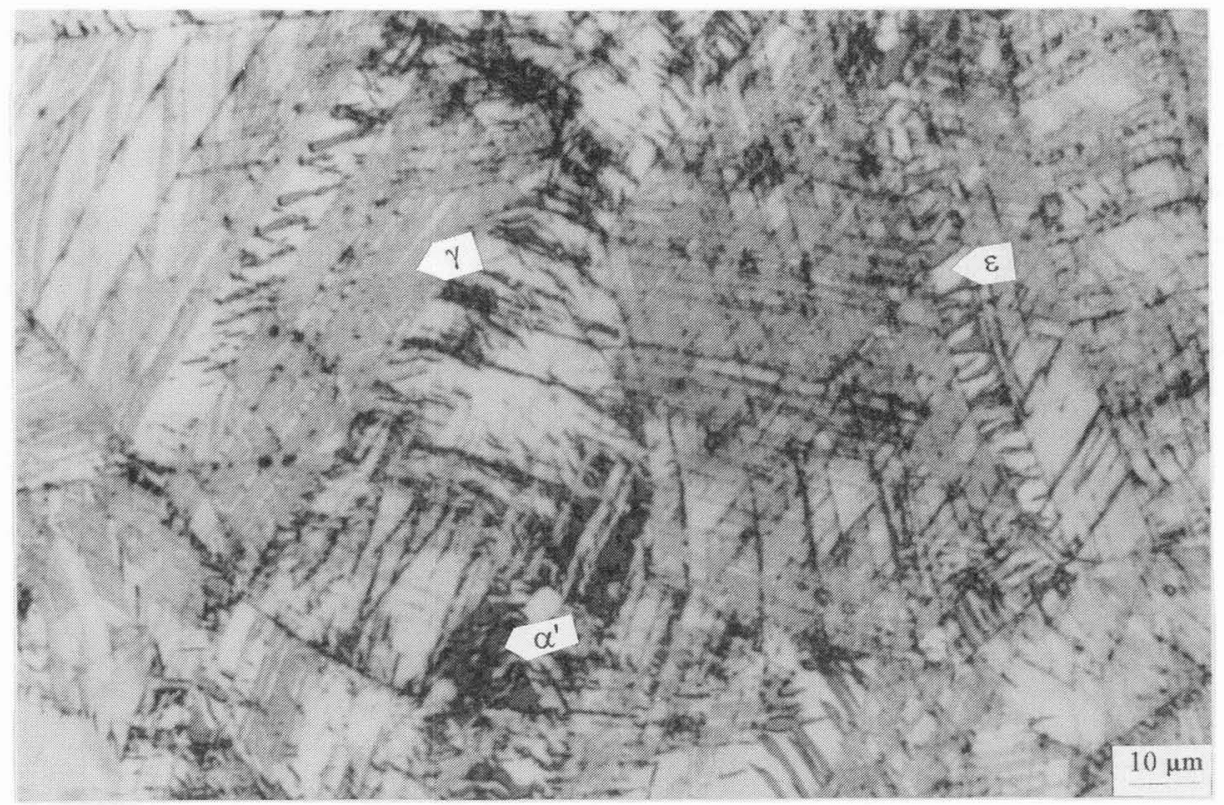

Fig. 2. The black and white print of a color micrography of the specimen deformed by $25 \%$ showing the formation of large amounts of $\alpha^{\prime}$-martensite (black particles and plates) inside and at the intersections of $\varepsilon$-martensite plates (white plates). Specimen pre-annealed at $1100^{\circ} \mathrm{C}, 30$ minutes, air cooled. 


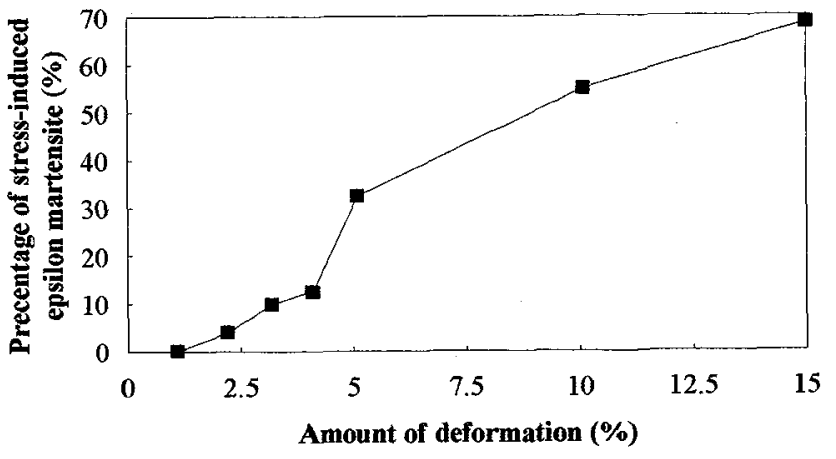

Fig.3. The relation of the amount of deformation with the percentage of stress-induced $\varepsilon$-martensite. Specimen pre-annealing condition: $600^{\circ} \mathrm{C}, 15$ minutes, air cooled

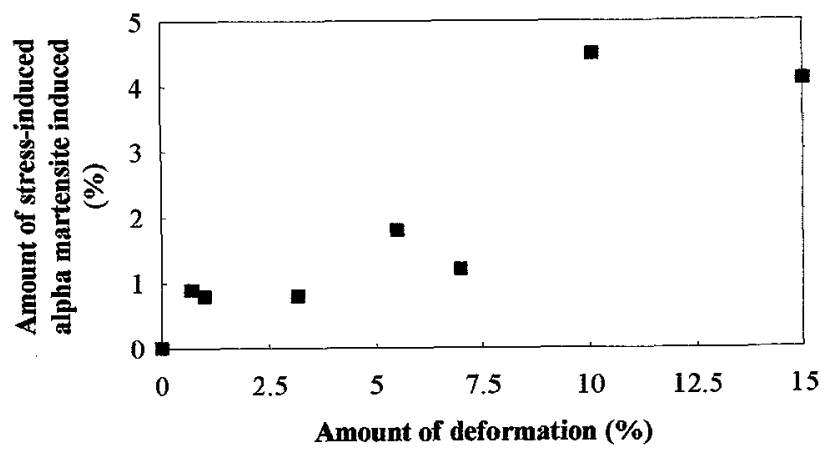

Fig.4. The relation of the amount of deformation with the amount of stress-induced $\alpha^{\prime}$-martensite. Specimen pre-annealing condition: $800^{\circ} \mathrm{C}, 15 \mathrm{~min}$, air cooled

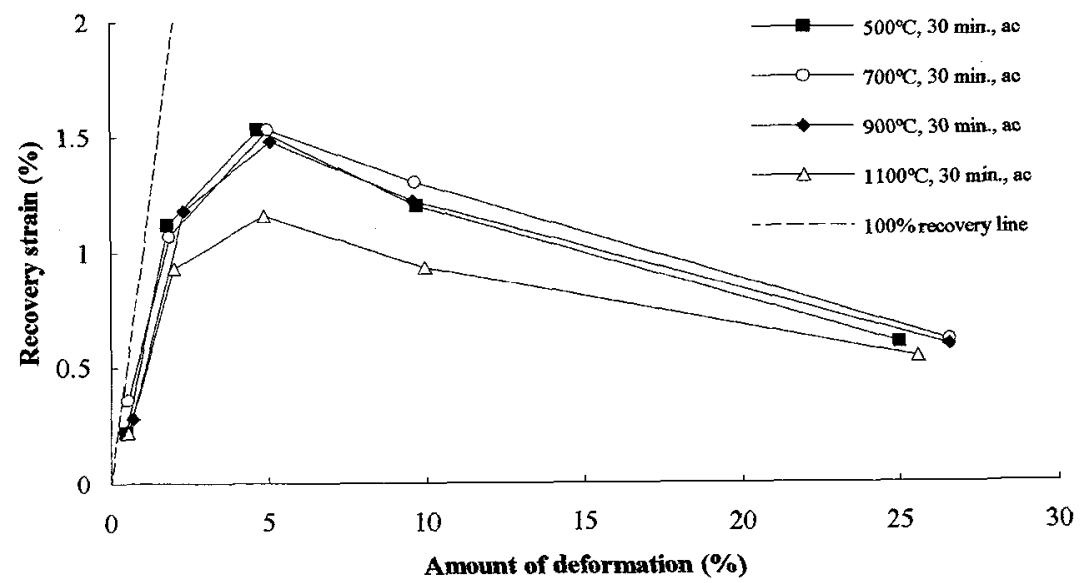

Fig.5. The relation of amount of deformation with the recovery strain. The specimens are pre-annealed at $500^{\circ} \mathrm{C}, 700^{\circ} \mathrm{C}, 900^{\circ} \mathrm{C}$ and $1100^{\circ} \mathrm{C}$ for 30 minutes and air cooled respectively. 